\title{
Oxidative and nitrosative stress in brain mitochondria of diabetic rats
}

\author{
R Mastrocola, F Restivo, I Vercellinatto, O Danni, \\ E Brignardello ${ }^{1}$, $\mathbf{M}$ Aragno and $\mathbf{G}$ Boccuzzi $^{1}$
}

Department of Experimental Medicine and Oncology, Section of General Pathology, Corso Raffaello 30, University of Turin, 10125 Turin, Italy

${ }^{1}$ Department of Clinical Pathophysiology, Via Genova 3, University of Turin, 10126 Turin, Italy

(Requests for offprints should be addressed to G Boccuzzi; Email: giuseppe.boccuzzi@unito.it)

\begin{abstract}
Diabetic encephalopathy, characterized by impaired cognitive functions and neurochemical and structural abnormalities, may involve direct neuronal damage caused by intracellular glucose. The study assesses the direct effect of chronic hyperglycemia on the function of brain mitochondria, the major site of reactive species production, in diabetic streptozotocin (STZ) rats. Oxidative stress plays a central role in diabetic tissue damage. Alongside enhanced reactive oxygen species (ROS) levels, both nitric oxide (NO) levels and mitochondrial nitric oxide synthase expression were found to be increased in mitochondria, whereas glutathione (GSH) peroxidase activity and
\end{abstract}

manganese superoxide dismutase protein content were reduced. GSH was reduced and GSH disulfide (GSSG) was increased in STZ rats. Oxidative and nitrosative stress, by reducing the activity of complexes III, IV and V of the respiratory chain and decreasing ATP levels, might contribute to mitochondrial dysfunction. In summary, this study offers fresh evidence that, besides the vasculardependent mechanisms of brain dysfunction, oxidative and nitrosative stress, by damaging brain mitochondria, may cause direct injury of neuronal cells.

Journal of Endocrinology (2005) 187, 37-44

\section{Introduction}

Besides well-described complications, such as autonomic and peripheral neuropathy, type I diabetes mellitus is also associated with gradually developing end-organ damage in the central nervous system (Brands et al. 2004). This little-known complication, referred to as 'diabetic encephalopathy', is characterized by impairment of cognitive functions and electrophysiologic changes (Allen et al. 2004). These functional changes are accompanied by neurochemical and structural abnormalities, as well as by degenerative changes in the brain (Weigner \& Jacobsen 1998, McCall 2004). Both micro- and macrovascular cerebral diseases occurring in diabetic patients and the direct neuronal damage caused by chronically elevated intracellular glucose concentrations are implicated in encephalopathy. However, it remains unclear how much of the neuronal impairment is caused directly by intracellular glucose. The direct glucose toxicity in the neurons is especially due to increased intracellular glucose oxidation (Nishikawa et al. 2000), which leads to an increase in reactive species production (Bonnefont-Rousselot 2002, Evans et al. 2002): in both man and experimentally diabetic rats, oxidative stress seems to play a central role in brain damage (Aragno et al. 2000a,b, 2002, Arvanitakis et al. 2004). Emerging evidence shows that the increased oxidative stress and consequent oxidative damage observed in hyperglycemic conditions begins in the mitochondria, which are the major site of ROS (reactive oxygen species) production (Raha \& Robinson 2000, Duchen 2004). Reactive species are byproducts of the mitochondrial respiratory chain that are physiologically counteracted by the intracellular antioxidant systems (Smith et al. 1999, Sarkela et al. 2001, Green et al. 2004). The overproduction of reactive species induced by enhanced glucose oxidation might overwhelm the antioxidant defenses, leading to cell damage. It has been reported that normalizing superoxide mitochondrial production blocks the pathways of hyperglycemic damage (Nishikawa et al. 2000). Recently, however, the unique role of brain mitochondrial dysfunction in experimental diabetes has been questioned, and it has been suggested that extramitochondrial factors may cooperate in the induction of oxidative stress associated with type I diabetes (Moreira et al. 2004).

This study aimed to characterize the oxidative stress induced by chronic hyperglycemia and its effects on the respiratory chain in the brain mitochondria of diabetic streptozotocin (STZ) rats. Results show that chronic hyperglycemia impairs the mitochondrial respiratory chain, induces oxidative damage through production of 
ROS and RNS (reactive nitrogen species) and damages mitochondrial functioning.

\section{Materials and Methods}

\section{Animal treatment}

Male Wistar rats (Harlan-Italy, Udine, Italy) weighing 200-220 g were cared for in compliance with the Italian Ministry of Health Guidelines (no. 86/609/EEC) and with the Principles of Laboratory Animal Care (NIH no. 85-23, revised 1985). They were provided with Piccioni pellet diet (no. 48, Gessate, Milan, Italy) and allowed water ad libitum. Hyperglycemia was induced through a single injection of STZ $(50 \mathrm{mg} / \mathrm{kg})$ in the tail vein. Three days later, glycemia was measured with o-toluidine reagent (Sigma kit, catalog no. 635) on blood collected from the heart $(200 \mu \mathrm{l})$. Only rats with blood glucose levels of $18-20 \mathrm{mmol} / 1$ entered the experimental protocols; normoglycemic rats were used as controls. After 21 days, control and hyperglycemic rats were anesthetized with ether and killed by decapitation after aortic exsanguination. Blood was collected and the plasma isolated. Glycemia was evaluated as described above. The cerebral hemispheres were chiseled and rapidly weighed and homogenized to obtain the mitochondrial fraction.

\section{Isolation of brain mitochondria}

Mitochondria were extracted from brain homogenates of normal and STZ rats by the method described by Morin et al. (2001). The homogenates $(17 \%, \mathrm{w} / \mathrm{v})$ were centrifuged at $2000 \mathrm{~g}$ for $3 \mathrm{~min}$. The supernatant A was preserved and the pellet diluted in $20 \mathrm{ml}$ buffer A $(20 \mathrm{mM}$ Tris- $\mathrm{HCl}, 250 \mathrm{mM}$ sucrose, $40 \mathrm{mM} \mathrm{KCl}, 2 \mathrm{mM}$ EGTA and $1 \mathrm{mg} / \mathrm{ml} \mathrm{BSA}, \mathrm{pH} 7 \cdot 2$, at $4{ }^{\circ} \mathrm{C}$ ) and centrifuged at $2000 \mathrm{~g}$ for $3 \mathrm{~min}$. Supernatant B was added to supernatant A and centrifuged at $12000 \mathrm{~g}$ for $10 \mathrm{~min}$. The pellet obtained was resuspended in $20 \mathrm{ml}$ of $15 \%$ (v/v) Percoll, and $3 \mathrm{ml}$ of this mixture were laid on two preformed layers of $3.5 \mathrm{ml}$ of $23 \%(\mathrm{v} / \mathrm{v})$ Percoll and $3.5 \mathrm{ml}$ of $40 \%(\mathrm{v} / \mathrm{v})$ Percoll. The gradient was centrifuged for $5 \mathrm{~min}$ at $30700 \mathrm{~g}$. The fraction between the two gradient layers was collected and diluted 1:4 with buffer $A$. The suspension was centrifuged twice at $12000 \mathrm{~g}$ for $10 \mathrm{~min}$, and the pellet (mitochondria-enriched fraction) was resuspended in $300 \mu \mathrm{l}$ buffer $\mathrm{B}\left(300 \mathrm{mM}\right.$ mannitol, $10 \mathrm{mM} \mathrm{KH}_{2} \mathrm{PO}_{4}$, $19 \mathrm{mM} \mathrm{KCl}$ and $5 \mathrm{mM} \mathrm{MgCl}_{2}, \mathrm{pH} \mathrm{7 \cdot 2)}$ at $4{ }^{\circ} \mathrm{C}$.

\section{Detection of nitric oxide (NO): total nitrite and oxidation of oxyhemoglobin}

Total nitrite concentration in fresh mitochondria was used as an indicator of nitric oxide (NO) synthesis. Nitrates in samples were stoichiometrically reduced to nitrites by incubating $250 \mu \mathrm{l}$ sample for $15 \mathrm{~min}$ at $37^{\circ} \mathrm{C}$, in the presence of $1 \mathrm{IU} / \mathrm{ml}$ nitrate reductase, $500 \mu \mathrm{M}$ NADPH and $50 \mu \mathrm{M}$ FAD in a final volume of $400 \mu \mathrm{l}$. When nitrate reduction was complete, unused NADPH, which interferes with subsequent nitrite determination, was oxidized with $100 \mathrm{IU} / \mathrm{ml}$ lactate dehydrogenase and $100 \mathrm{mM}$ sodium pyruvate in a final reaction volume of $500 \mu \mathrm{l}$ and incubated for $5 \mathrm{~min}$ at $37^{\circ} \mathrm{C}$ (Millar \& Thiemermann 1997). Subsequently, total nitrites were assayed by adding $500 \mu \mathrm{l}$ Griess reagent (4\% sulfanilamide and $0 \cdot 2 \%$ naphtylendiamide in $10 \%$ phosphoric acid) to each sample (Green et al. 1981).

Production of NO was measured in fresh brain mitochondria by monitoring the oxidation of oxyhemoglobin to methemoglobin spectrophotometrically at $37^{\circ} \mathrm{C}$ in a reaction medium containing $50 \mathrm{mM}$ phosphate buffer, $1 \mathrm{mM} \mathrm{CaCl}, 1 \mathrm{mM}$ L-arginine, $100 \mu \mathrm{M} \mathrm{NADPH}$, $10 \mu \mathrm{M}$ dithiotreitol, $4 \mu \mathrm{M}$ superoxide dismutase (SOD), $0.1 \mu \mathrm{M}$ catalase, mitochondria $(1.0 \mathrm{mg}$ prot $/ \mathrm{ml})$, and $5 \mu \mathrm{M}$ oxyhemoglobin (expressed per heme group). The kinetics was monitored at $577 \mathrm{~nm}(\varepsilon=11.2 \mathrm{mM} / \mathrm{cm})$, and absorbance changes were expressed as $\mathrm{nmol} \mathrm{NO} / \mathrm{min}$ per mg prot. Control experiments adding $1 \mathrm{mM} \mathrm{NG-methyl-}$ L-arginine (L-NMMA) were performed to confirm that hemoglobin oxidation occurred only by NO formation. Addition of L-NMMA inhibited the rate of hemoglobin oxidation by $90 \%$ (Arnaiz et al. 1999).

\section{Western blot analysis}

Mitochondrial nitric oxide synthase (MtNOS) and manganese superoxide dismutase (MnSOD) were detected on fresh mitochondria by Laemmli's (1970) method. Aliquots of sample containing $\cong 30 \mu \mathrm{g}$ proteins were resolved respectively on $7 \cdot 5 \%$ and $10 \%$ SDSpolyacrylamide gel, and then blotted onto nitrocellulose membranes (Amersham Biosciences, Braunschweig, Germany). The membranes were blocked with $5 \%(\mathrm{w} / \mathrm{v})$ nonfat dry milk in $5 \mathrm{mM}$ Tris- $\mathrm{HCl}, \mathrm{pH} 7 \cdot 4$, containing $200 \mathrm{mM} \mathrm{NaCl}$ and $0 \cdot 05 \%(\mathrm{v} / \mathrm{v})$ Tween 20 (TBS-Tween) for $1 \mathrm{~h}$ at $25^{\circ} \mathrm{C}$ and then incubated with mouse monoclonal antibody against mtNOS diluted 1:1000 (Santa Cruz Biotechnology, Santa Cruz, CA, USA) or rabbit polyclonal antibody against MnSOD diluted 1:10 000 (Upstate, Lake Placid, NY, USA). The membranes were incubated with appropriate peroxidase-labeled secondary antibody prepared in TBS-Tween containing $2 \%(\mathrm{w} / \mathrm{v})$ nonfat dry milk. Immunoreactive proteins were detected with a chemiluminescence assay (ECL, Amersham) and subsequent exposure to film for 2-10 min. Specific bands were quantified by densitometry using analytic software (Bio-Rad, Multi-Analyst, Munich, Germany).

\section{Pro-oxidant and antioxidant compounds}

The pro-oxidant state was determined by monitoring the generation of hydrogen peroxide $\left(\mathrm{H}_{2} \mathrm{O}_{2}\right)$ after adding 
$100 \mu \mathrm{l}$ sample at $30^{\circ} \mathrm{C}$ to a cuvette containing a respiration buffer: $7 \cdot 4 \mathrm{IU}$ horseradish peroxidase, $40 \mu \mathrm{M}$ acetylated ferrocytochrome- $c$ and $5 \mu \mathrm{M} \quad p$-hydroxyphenylacetic acid. $\mathrm{H}_{2} \mathrm{O}_{2}$ release was evaluated as the increase of acetylated ferrocytochrome- $c$ oxidation rate, and monitored at 550 minus $540 \mathrm{~nm}$ with an absorption coefficient of $19.9 \mathrm{mmol} / 1$ per $\mathrm{cm}$, as described by Zoccarato et al. (1993).

The glutathione (GSH)/glutathione disulfide (GSSG) ratio was evaluated by the Owens and Belcher (1965) method. A mixture was directly prepared in a cuvette: 0.05 M Na-phosphate buffer, $\mathrm{pH}$ 7.0; $1 \mathrm{mM}$ EDTA, pH $7 \cdot 0$; and $10 \mathrm{mM}$ DTNB plus an aliquot of the sample. GSH content was evaluated after $2 \mathrm{~min}$ at $412 \mathrm{~nm}$ and expressed as $\mu \mathrm{g} / \mathrm{mg}$ prot. Suitable volumes of diluted GSH reductase and of NADPH were then added to evaluate the total GSH level. The difference between total GSH and GSH content represents the GSSG content (expressed as $\mu \mathrm{g} / \mathrm{mg}$ prot); the ratio between GSSG content and GSH is considered a good measure of antioxidant status.

GSH peroxidase activity was determined on freezethawed and sonicated samples. Mitochondria were suspended in $1 \mathrm{ml}$ buffer (50 mM Tris- $\mathrm{HCl}, \mathrm{pH} 7 \cdot 6 ; 5 \mathrm{mM}$ EDTA; $1 \mathrm{mM}$ GSH; $0.22 \mathrm{mM} \mathrm{NaDPH}$; and $0.4 \mathrm{U}$ of GSH reductase), and the reaction was initiated by adding tert-butyl-hydroperoxide to a final concentration of $0 \cdot 22 \mathrm{mM}$. NADPH consumption was monitored continuously over $3 \mathrm{~min}$ at $340 \mathrm{~nm}$ in a spectrophotometer. Final results are expressed as units/mg protein of mitochondrial protein (Yang et al. 2000).

\section{Mitochondrial complexes}

Mitochondrial complex II was measured as the rate of cytochrome $c$ reduction at $550 \mathrm{~nm}$ and $37^{\circ} \mathrm{C}$ (Morin et al. 2002). The reaction mixture $(1 \mathrm{ml})$ contained the following: $10 \mathrm{mM}$ Tris $-\mathrm{HCl}, \mathrm{pH} 7 \cdot 2 ; 0 \cdot 2 \mathrm{mM}$ ADP; $3 \mu \mathrm{M}$ rotenone; $0.3 \mathrm{mM} \mathrm{KCN} ; 10 \mathrm{mM}$ succinate; and $40 \mu \mathrm{g}$ mitochondrial protein (samples were freeze-thawed and sonicated). The reaction was initiated by adding $40 \mu \mathrm{M}$ cytochrome $c$ to the cuvette. After $1 \mathrm{~min}, 10 \mathrm{mM}$ malonate were added, and the inhibited rate was measured for $1 \mathrm{~min}$, after which $50 \mu \mathrm{M}$ succinate were added, and the rate was measured again for $1 \mathrm{~min}$.

Mitochondrial complex III (cytochrome $c$ reductase) was measured as the rate of cytochrome $c$ reduction at $550 \mathrm{~nm}$ and $37^{\circ} \mathrm{C}$ (Morin et al. 2002). The reaction mixture $(1 \mathrm{ml})$ contained the following: $10 \mathrm{mM}$ Tris$\mathrm{HCl}, \mathrm{pH} 7.2 ; 0.2 \mathrm{mM}$ ADP; $3 \mu \mathrm{M}$ rotenone; $0.3 \mathrm{mM}$ $\mathrm{KCN}$; $10 \mathrm{mM}$ succinate; and $40 \mu \mathrm{g}$ mitochondrial protein (samples were freeze-thawed and sonicated). The reaction was initiated by adding $40 \mu \mathrm{M}$ cytochrome $c$ to the cuvette. After $1 \mathrm{~min}, 10 \mathrm{mM}$ malonate were added, and the inhibited rate was measured for $1 \mathrm{~min}$, after which $50 \mu \mathrm{M}$ decylubiquinol were added, and the rate was measured again for $1 \mathrm{~min}$.
Mitochondrial complex IV (cytochrome $c$ oxidase) was measured as the rate of cytochrome $c$ oxidation at $550 \mathrm{~nm}$ and $37^{\circ} \mathrm{C}$ (Morin et al. 2002). The reaction mixture in the cuvette contained the following: $10 \mathrm{mM}$ potassium phosphate buffer, $\mathrm{pH} 7 \cdot 2$, and $40 \mu \mathrm{M}$ reduced cytochrome $c$. The reaction was initiated by the addition of $40 \mu \mathrm{g}$ mitochondrial protein (samples were freeze-thawed and sonicated), and the rate was measured for $1 \mathrm{~min}$.

Mitochondrial complex V activity (ATP synthase) was measured as the hydrolysis rate of ATP to ADP plus inorganic phosphate (Pi), as described by Morin et al. (2002). Freeze-thawed and sonicated mitochondria (50 $\mu \mathrm{g}$ protein) were incubated in $500 \mu$ ATPase buffer $(50 \mathrm{mM}$ Tris and $5 \mathrm{mM} \mathrm{MgCl}_{2}, \mathrm{pH} 7 \cdot 5$ ) at $37^{\circ} \mathrm{C}$ with $5 \mathrm{mM} \mathrm{ATP}$ for $10 \mathrm{~min}$. The reaction was halted by adding $500 \mathrm{ml}$ of $10 \%(\mathrm{w} / \mathrm{v})$ trichloroacetic acid. Each assay was centrifuged at $3000 \mathrm{~g}$ for $20 \mathrm{~min}$, and $500 \mu \mathrm{l}$ supernatant were mixed with $500 \mu \mathrm{l}$ water. Pi production was measured as described by Fiske and Subbarow (1925), and $1.6 \mathrm{ml}$ of $10.1 \mathrm{mM}$ ammonium molybdate in $0.42 \mathrm{M}$ sulfuric acid were added. The reaction measuring the Pi production was started by adding $400 \mu \mathrm{l}$ of a mixture containing $0.72 \mathrm{M}$ sodium bisulfite, $41.6 \mathrm{mM}$ sodium sulfite and $11 \cdot 0 \mathrm{mM}$ 4-amino-3-hydroxy-1-naphtalenesulfonic acid. After 10-min incubation at room temperature, the $\mathrm{Pi}$ production was monitored at $660 \mathrm{~nm}$.

\section{Mitochondrial damage}

Cytochrome $c$ release was measured in the cytosol fraction obtained by centrifugation during mitochondria isolation, as described by Perez-Pinzon et al. (1999). Briefly, $1 \mathrm{ml}$ cytosol was transferred to a spectrophotometer cuvette, and the absorption peak was measured at $419 \mathrm{~nm}$. The final cytochrome $c$ concentration was obtained from a standard curve and was expressed as $\mathrm{nmol} / \mathrm{mg}$ protein.

ATP concentration was determined by Debetto et al.'s (1982) method: $3 \cdot 5 \%(\mathrm{v} / \mathrm{v})$ perchloric acid was added to an aliquot of sample and immediately cooled on ice for $40 \mathrm{~min}$. The acid supernatant was neutralized with $\mathrm{K}_{2} \mathrm{CO}_{3}(\mathrm{O} .5 \mathrm{M})$ and the suspension centrifuged to remove insoluble material. The sample $(10 \mu \mathrm{l})$ was injected into the HPLC column; eluent: potassium phosphate buffer $0 \cdot 1 \mathrm{M}, \mathrm{pH} 5 \cdot 3$; column: symmetry $\mathrm{C} 18$ (Waters column $5 \mu \mathrm{m}, 3.9 \times 150 \mathrm{~mm}$ ).

\section{Statistical analysis}

All results are presented as means \pm S.D. Differences between means were analyzed for significance by Student's t-test (Matthews \& Farewell 1988).

\section{Results}

\section{Biochemical parameters}

The body weight of STZ diabetic rats was significantly lower than that of controls 21 days after injection of STZ 
(control group: $250 \cdot 9 \pm 12 \cdot 4 \mathrm{~g} ;$ STZ: $224 \cdot 7 \pm 10 \cdot 4 \mathrm{~g}$ ). STZ was rapidly eliminated from the body: about $80 \%$ appeared in the urine within $6 \mathrm{~h}$ (Oberley 1988). Blood glucose levels in STZ-treated rats 3 days after STZinjection were $18-20 \mathrm{mmol} / \mathrm{l}$. The glucose level remained unchanged during the 21-day period. At the end of the protocol (21 days), the glycemia level was $6.04 \pm 0.64 \mathrm{mmol} / 1$ in the control group and $20 \cdot 72 \pm 2.25 \mathrm{mmol} / 1$ in the STZ-treated group.

\section{NO synthesis}

Figure 1 illustrates the levels of NO in the enriched fraction of mitochondria isolated from the brain of normal and diabetic rats. Panel A shows the enhanced level of total nitrite level $\left(\mathrm{NO} 2 / \mathrm{NO}_{3}\right)$ in STZ-rats versus control rats. $\mathrm{NO}_{2} / \mathrm{NO}_{3}$ are the primary oxidation products of $\mathrm{NO}$ after reaction with oxygen, and thus the nitrite-plus-nitrate concentration is usually employed as indicator of NO synthesis (Green et al. 1981). Panel B shows NO production evaluated in terms of oxidation of oxymyoglobin to methemoglobin. In STZ rats, the production of $\mathrm{NO}$ was more than double that of the control group. Panel C reports a representative experiment showing that $\mathrm{mtNOS}$ in STZ rats appeared to be more expressed than in controls. All isoforms of NOS may be expressed in the brain. Brain mtNOS was identified mainly as nNOS, which can be regulated by a variety of stimuli and by several physiologic conditions (Cooper 2002). The mtNOS isoform is expressed constitutively and has been located in the inner mitochondrial membrane (Giulivi et al. 1998).

\section{Antioxidant and pro-oxidant levels}

GSSG/GSH ratio, MnSOD and $\mathrm{H}_{2} \mathrm{O}_{2}$ levels were determined in the enriched mitochondrial fraction (Fig. 2). The ratio GSSG/GSH (panel A) was increased, since the GSSG level was increased and the GSH level reduced in STZ rats versus controls. The content of MnSOD (panel B), a specific mitochondrial antioxidant enzyme, was markedly lower in STZ rats. Moreover, a marked increased of hydrogen peroxide, the product of dismutation of superoxide by MnSOD, was observed (panel C), further indicating that radical species overproduction consumes endogenous antioxidants and overwhelms the antioxidant capability. The activity of GSH peroxidase was also reduced in the mitochondrial fraction of diabetic rats versus controls (Table 1).

\section{Respiratory chain}

The activity of complex II, III, IV and V is shown in Table 1. The complex II did not show significant change versus controls. Complex III activity (cytochrome $c$

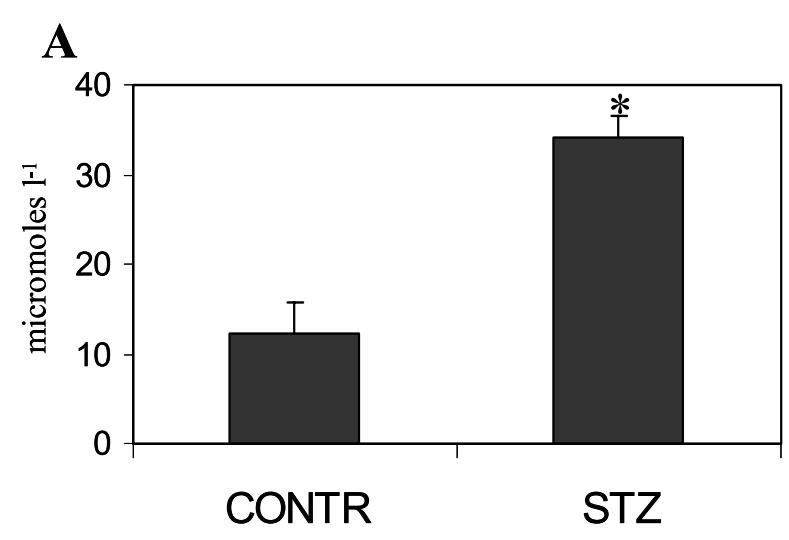

\section{B}

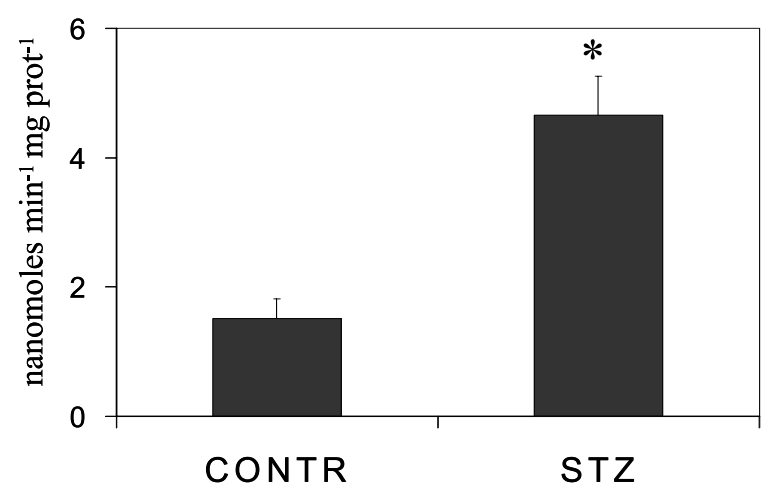

C
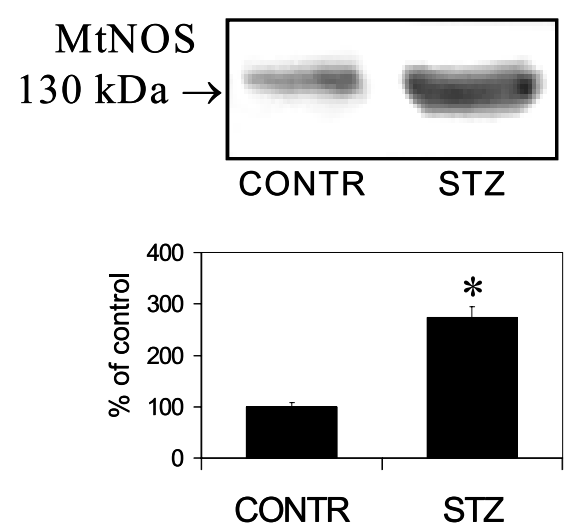

Figure 1 Effect of STZ-induced diabetes on NO level. (A) $\mathrm{NO}_{2} / \mathrm{NO}_{3}$ level; (B) $\mathrm{NO}$ production; (C) representative Western blot showing mtNOS levels. The histogram shows the band densities of 6-7 experiments compared with relative $\beta$-actin band densities and expressed as percent variation versus the control group. Data are means \pm S.D. of $6-7$ rats per group. ${ }^{*} P<0 \cdot 05$, statistically significant versus control rats.

reductase) fell from $66.72 \pm 13.97$ in control rats to $31 \cdot 19 \pm 5.09$ in STZ rats (50\% lower). Complex IV 
A

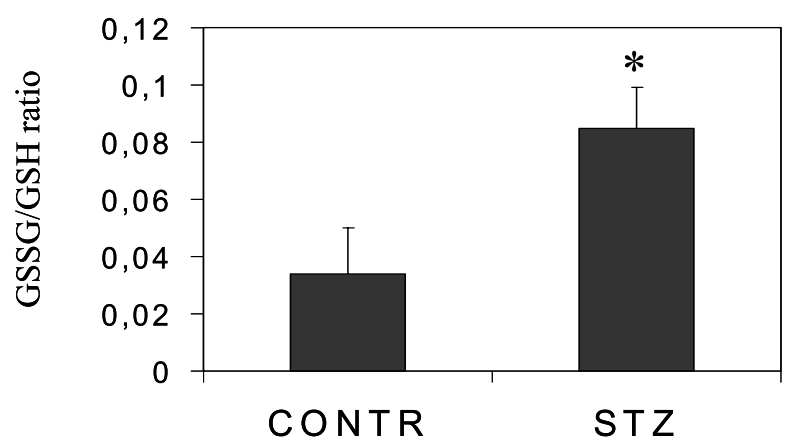

B
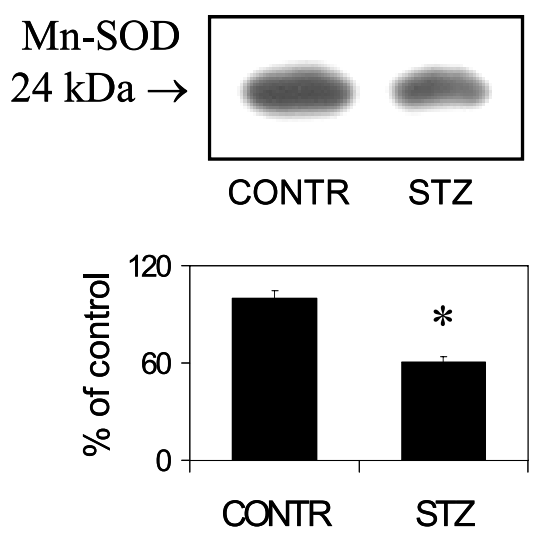

C

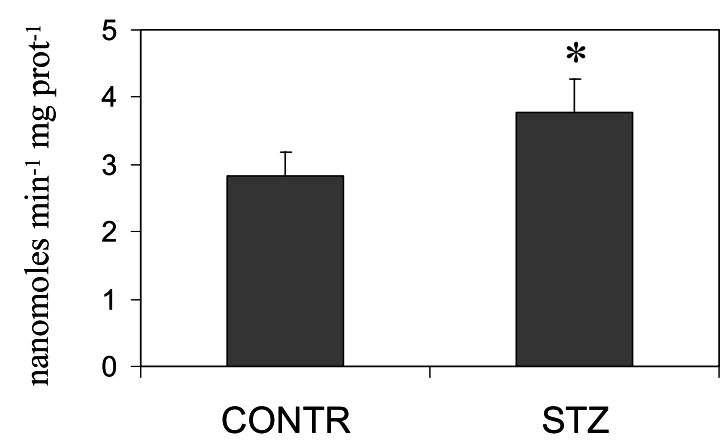

Figure 2 Effect of STZ-induced diabetes on antioxidant and pro-oxidant levels. (A) GSSG/GSH ratio; (B) representative Western blot showing MnSOD levels. The histogram shows the band densities of 6-7 experiments compared with relative $\beta$-actin band densities and expressed as percent variation versus the control group. (C) $\mathrm{H}_{2} \mathrm{O}_{2}$ levels. Data are means \pm S.D. of $6-7$ rats per group. ${ }^{*} P<0 \cdot 05$, statistically significant versus controls.

(cytochrome $c$ oxidase) and complex V (ATP synthase) activities were also significantly reduced (by 30\%) in diabetic rats versus controls.
Table 1 Effect of STZ-induced diabetes on respiratory mitochondrial enzymatic activities and on antioxidant enzyme activity

\begin{tabular}{|c|c|c|}
\hline & CONTROL & STZ \\
\hline $\begin{array}{l}\text { Complex II } \\
\text { (nmol/min/mg protein) }\end{array}$ & $355 \cdot 45 \pm 36 \cdot 41$ & $443 \cdot 65 \pm 65 \cdot 54$ \\
\hline $\begin{array}{l}\text { Complex III-Cyt c-reductase } \\
(\mathrm{nmol} / \mathrm{min} / \mathrm{mg} \text { protein) }\end{array}$ & $66 \cdot 72 \pm 13 \cdot 97$ & $31 \cdot 19 \pm 5 \cdot 09^{*}$ \\
\hline $\begin{array}{l}\text { Complex IV-Cyt c-oxidase } \\
\text { (nmol/min/mg protein) }\end{array}$ & $213 \cdot 56 \pm 14 \cdot 69$ & $160 \cdot 56 \pm 33 \cdot 57^{*}$ \\
\hline $\begin{array}{l}\text { Complex V-ATP-synthase } \\
\text { (nmol Pi/min/mg protein) }\end{array}$ & $2 \cdot 79 \pm 0 \cdot 18$ & $1 \cdot 79 \pm 0 \cdot 25^{*}$ \\
\hline $\begin{array}{l}\text { GSH peroxidase } \\
\text { (U/mg protein })\end{array}$ & $14 \cdot 66 \pm 0 \cdot 93$ & $10 \cdot 31 \pm 1 \cdot 40^{\star}$ \\
\hline
\end{tabular}

Data are mean \pm S.D. of 6-7 rats per group

${ }^{*} P<0 \cdot 05$, statistically significant versus control rats.

\section{Mitochondrial function}

To evaluate the entity of mitochondrial dysfunction, ATP level and cytochrome $c$ release in the cytosol were measured. ATP levels in mitochondria of STZ rats were decreased versus the control group (Fig. 3, panel A), and the cytochrome $c$ level in the cytosol was increased (Fig. 3, panel B). Release of cytochrome $c$ into the cytosol from mitochondria is considered a good marker of mitochondrial membrane damage (Perez-Pinzon et al. 1999).

\section{Discussion}

The study confirms that mitochondria isolated from the brain of hyperglycemic rats show increased ROS levels, associated with reduced antioxidant barriers, in terms of GSSG/GSH ratio, GSH peroxidase activity and MnSOD content. Moreover, besides the enhanced level of ROS, NO levels are also increased, and expression of mtNOS appears to be significantly increased in the brain mitochondria of diabetic rats. $\mathrm{NO}$ is a diffusible regulatory molecule involved in a wide range of physiologic and pathologic events (Sarkela et al. 2001). Originally known as endothelian relaxation factor, it has been shown to be an intracellular messenger in physiologic processes such as regulation of blood flow and neurotransmission (Brown 1999). The borderline between the physiologic and pathologic activities of NO is still a matter of controversy, but it is generally accepted that both its concentration and subcellular production site are critical in determining whether it acts as a signaling or a neurotoxic molecule. It now appears certain that, in neurons, $\mathrm{NO}$ is generated in mitochondria by NO synthase (NOS) in the inner membrane of the mitochondria (Giulivi et al. 1998). NO, at low and physiologic concentrations, reversibly binds to the $\mathrm{Cu}_{\mathrm{B}}$ center of cytochrome $c$ oxidase (complex IV) and can partially inhibit electron transfer to $\mathrm{O}_{2}$, acting in competition with oxygen (50-100 nM NO inhibits 50\% 


\section{A}

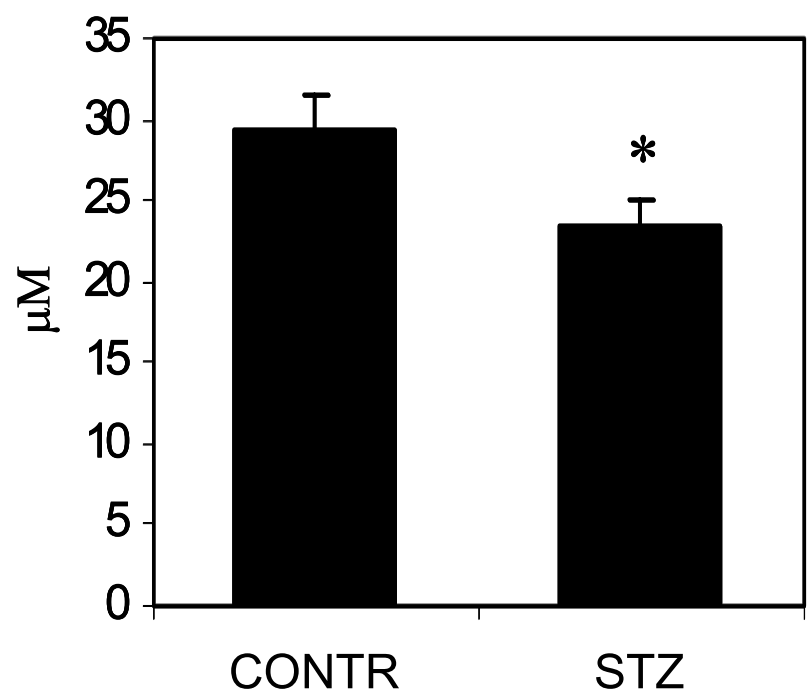

\section{B}

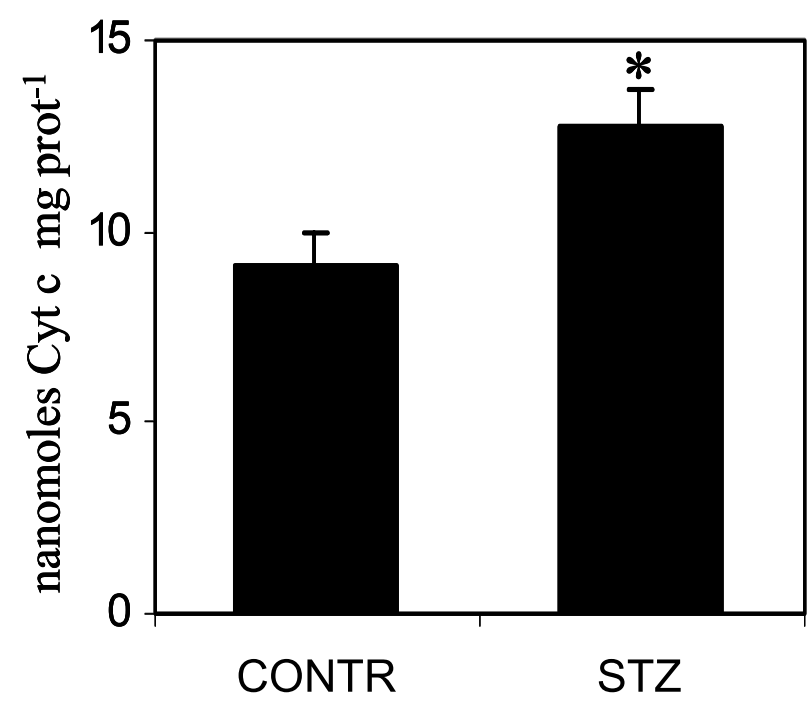

Figure 3 Effect of STZ-induced diabetes on ATP concentration (A) and cytochrome $c$ release (B). Data are means \pm S.D. of 6-7 rats per group. ${ }^{*} P<0 \cdot 05$, statistically significant versus controls.

of cytochrome $c$ oxidase activity) (Moncada \& Erusalimsky 2002). At those concentrations, NO sets up cytochrome $c$ oxidase activity and participates in maintaining radical matrix steady state.

In diabetic rat brain mitochondria, we show here that NOS activity increases, with consequent NO hyperproduction: in those conditions, NO inhibits cytochrome $c$ oxidase activity but might also act on other mitochondrial components, inhibiting other respiratory chain complexes by nitrosilation or oxidizing protein thiols (Clancy et al. 1994). In line with this finding, we observed a reduction in the activities of complex III (cytochrome $c$ reductase), IV (cytochrome $c$ oxidase) and V (ATP synthase) of the respiratory chain, leading to the impairment of the cell energy state. Beside its effects on the respiratory chain, NO may also contribute to cell damage in diabetes, modulating glucose entry into the cells. Indeed, NO has been shown to upregulate glucose transporters in neurons (Bolaños et al. 2004). This activity has been regarded as protective in conditions (such as cerebral ischemia) in which the glucose supply to the brain is reduced (Friberg et al. 2002). Conversely, the upregulation of glucose transporters by $\mathrm{NO}$ might be detrimental in conditions characterized by excessive glucose supply, such as diabetes, in which increased intracellular glucose leads to an oversupply of electrons in the mitochondrial transfer chain, resulting in mitochondrial membrane hyperpolarization and a further increase in free-radical production.

On the other hand, altered NOS expression and activity increase peroxynitrite production, which overwhelms the detoxifying reactions so that the effects mediated by $\mathrm{NO}$-derived reactive species prevail. Indeed, peroxynitrite, a harmful oxidant formed by reaction between superoxide and NO, reacts with a variety of molecules, including protein and non-protein-thiols, unsaturated fatty acids and DNA, thus affecting energy conservation mechanisms and oxidative post-translation modification of protein, and ultimately causing neuronal cell death (Murray et al. 2003).

Besides its direct detrimental effect on mitochondrial function, RNS interplays with the simultaneous oxidative stress, amplifying mitochondrial damage. Indeed, peroxynitrite can inhibit MnSOD, thereby reducing its quenching activity on superoxide. Here we show that MnSOD content is reduced in mitochondria, suggesting that the dismutation of superoxide, overproduced as a result of glucose-induced oxidative stress, might be impaired. The role of mitochondrial $\mathrm{MnSOD}$ is critical in protecting neurons from free-radical damage: mutations which affect SOD, with consequent increase of reactive species, have been reported in a number of neurologic diseases (Raha et al. 2000). The increased $\mathrm{H}_{2} \mathrm{O}_{2}$ is related to the drastic loss of GSH, which is required to activate GSH peroxidase, the $\mathrm{H}_{2} \mathrm{O}_{2}$ detoxifying enzyme. In fact, we also observed the activity of GSH peroxidase to be clearly affected in STZ rats. However, GSH loss might to be partially dependent on the opening of the mitochondrial permeability transition pore (Moreira et al. 2005), as suggested by the observation of a higher release of cytochrome $c$ in mitochondria isolated from STZ rats. The mitochondrial pool of GSH is considered vital for cell survival: after severe mitochondrial GSH depletion, cell death occurs; this, however, is delayed by antioxidant treatment (Han et al. 1997, 2003). 
Moreover, the brain mitochondria of diabetic rats show consistently reduced ATP levels, as a result of the prominent changes in activity of the mitochondrial respiratory chain enzymes in such rats. ATP content is closely related to maintenance of membrane potential; thus, a reduction in ATP would produce an irreversible drop in membrane potential, opening the permeability transition pore and triggering mechanisms of cell death. Indeed, we also observed increased cytochrome $c$ release into the cytosol. Cytochrome $c$ is a marker of mitochondrial dysfunction (Yang et al. 1997) and a cell-death trigger activator that operates through activation of specific caspases and consequent induction of apoptosis (Kluck et al. 1997).

In brief, this study offers fresh evidence that oxidative stress and nitrosative stress cooperate in damaging the brain mitochondria of diabetic rats. These findings may account for the direct injury of neuronal cells that is added to the micro- and macrovascular damage. Further studies are needed to establish whether the damage to mitochondria causes or exacerbates diabetic encephalopathy.

\section{Acknowledgements}

This work was supported in part by FIRB-2001, MIUR (Ministero dell'Istruzione, Università e Ricerca) and the Regione Piemonte, Italy. The authors declare that there is no conflict of interest that would prejudice the impartiality of this scientific work.

\section{References}

Allen KV, Frier BM \& Strachan MWJ 2004 The relationship between type 2 diabetes and cognitive dysfunction: longitudinal studies and their methodological limitations. European Journal of Pharmacology 490 169-175.

Aragno M, Parola S, Brignardello E, Mauro A, Tamagno E, Manti R, Danni O \& Boccuzzi G 2000a Dehydroepiandrosterone prevents oxidative injury induced by transient ischemia/ reperfusion in the brain of diabetic rats. Diabetes 49 1924-1931.

Aragno M, Parola S, Tamagno E, Brignardello E, Manti R, Danni O \& Boccuzzi G $2000 b$ Oxidative derangement in rat synaptosomes induced by hyperglycaemia: restorative effect of dehydroepiandrosterone treatment. Biochemical Pharmacology $\mathbf{6 0}$ 389-395.

Aragno M, Mastrocola R, Brignardello E, Catalano MG, Robino G, Manti R, Parola M, Danni O \& Boccuzzi G 2002

Dehydroepiandrosterone modulates nuclear factor-kB activation in hippocampus of diabetic rats. Endocrinology 143 3250-3258.

Arnaiz SL, Coronel MF \& Boveris A 1999 Nitric oxide, superoxide, and hydrogen peroxide production in brain mitochondria after haloperidol treatment. Nitric oxide: Biology and Chemistry 3 235-243.

Arvanitakis Z, Wilson RS, Bienias JL, Evans DA \& Bennett DA 2004 Diabetes mellitus and risk of Alzheimer disease and decline in cognitive function. Archives of Neurology 61 661-666.

Bolaños JP, Cidad P, Garçia-Nogales P, Delgado-Esteban M, Fernandez E \& Almeida A 2004 Regulation of glucose metabolism by nitrosative stress in neural cells. Molecular Aspects in Medicine $\mathbf{2 5}$ $61-73$.
Bonnefont-Rousselot D 2002 Glucose and reactive oxygen species. Current Opinion in Clinical Nutrition and Metabolic Care 5 561-568.

Brands AMA, Kessels RPC, De Haan EHF, Kappelle LJ \& Biessels GJ 2004 Cerebral dysfunction in type I diabetes: effects of insulin, vascular risk factors and blood-glucose levels. European Journal of Pharmacology 490 159-168.

Brown GC 1999 Nitric oxide and mitochondrial respiration. Biochimica et Biophysica Acta 1411 351-369.

Clancy RM, Levartosky D, Leszczynska-Piziak J, Yegudin J \& Abramson S 1994 Nitric oxide reacts with intracellular glutathione and activates the hexose monophosphate shunt in human neutrophils: evidence for $S$-nitrosoglutathione as a bioactive intermediary. PNAS 91 3680-3684.

Cooper CE 2002 Nitric oxide and cytochrome oxidase: substrate, inhibitor or effector? Trends in Biochemical Sciences 27 33-39.

Debetto P, Dal Toso R, Varotto R, Bianchi V \& Luciani S 1982 Effects of potassium dichromate on ATP content of mammalian cells cultured in vitro. Chemico-Biological Interactions 41 15-24.

Duchen MR 2004 Role of mitochondria in health and disease. Diabetes 53 S96-S102.

Evans JL, Goldfine ID, Maddux BA \& Grodsky GM 2002 Oxidative stress and stress-activated signaling pathways: a unifying hypothesis of type 2 diabetes. Endocrine Reviews 23 599-622.

Fiske CH \& Subbarow Y 1925 The colorimetric determination of phosphorus. Journal of Biological Chemistry 66 1225-1230.

Friberg H, Wieloch T \& Castilho RF 2002 Mitochondrial oxidative stress after global brain ischemia in rats. Neuroscience Letters 334 111-114.

Giulivi C, Poderoso JJ \& Boveris A 1998 Production of nitric oxide by mitochondria. Journal of Biological Chemistry 273 11038-11043.

Green C, Brand MD, Murphy MP 2004 Prevention of mitochondrial damage as a therapeutic strategy in diabetes. Diabetes 53 110-118.

Green LC, Ruiz De Luzuriaga K \& Wagner DA 1981 Nitrate biosynthesis in man. PNAS 78 7764-7768.

Han D, Sen CK, Roy S, Kobayashi MS, Tritschler HJ \& Packer L 1997 Protection against glutamate-induced cytotoxicity in C6 glial cells by thiol antioxidants. American Journal of Physiology - Regulatory, Integrative and Comparative Physiology 273 R1771-R17778.

Han D, Canali R, Rettori D \& Kaplowitz N 2003 Effect of glutathione depletion on sites and topology of superoxide and hydrogen peroxide production in mitochondria. Molecular Pharmacology 64 1136-1144.

Kluck RM, Bossiwetzel E, Green DR \& Newmeyer DD 1997 The release of cytochrome $c$ from mitochondria: a primary site for Bcl-2 regulation of apoptosis. Science 275 1132-1136.

Laemmli UK 1970 Cleavage of structural proteins during the assembly of the head of bacteriophage $\mathrm{T}_{4}$. Nature $\mathbf{2 2 7}$ 680-685.

Matthews DE \& Farewell VT 1988 Linear regression models for medical data. In Using and Understanding Medical Statistics, pp 134-140. Basel: Karger.

McCall AL 2004 Cerebral glucose metabolism in diabetes mellitus. European Journal of Pharmacology 490 147-158.

Millar CGM \& Thiemermann C 1997 Intrarenal haemodynamics and renal dysfunction in endotoxaemia: effects of nitric oxide synthase inhibition. British Journal of Pharmacology 121 1824-1830.

Moncada S \& Erusalimsky JD 2002 Does nitric oxide modulate mitochondrial energy generation and apoptosis? Nature $\mathbf{3}$ 214-220.

Moreira PI, Santos MS, Moreno AM, Proença T, Seiça R \& Oliveira R 2004 Effect of streptozotocin-induced diabetes on rat brain mitochondria. Journal of Neuroendocrinology 16 32-38.

Moreira PI, Custodio JB, Oliveira CR \& Santos MS 2005 Brain mitochondrial injury induced by oxidative stress-related events is prevented by tamoxifen. Neuropharmacology 48 435-447. 
Morin C, Zini R, Simon N \& Tillement JP 2002

Dehydroepiandrosterone and $\alpha$-estradiol limit the functional alterations of rat brain mitochondria submitted to different experimental stresses. Neuroscience 115 415-424.

Murray J, Taylor SW, Zhang B \& Ghosh S 2003 Oxidative damage to mitochondrial complex I due to peroxynitrite. Journal of Biological Chemistry 278 37223-37230.

Nishikawa T, Edelstein D, Du XL, Yamagishi S, Matsumura T, Kaneda Y, Yorek MA, Beebe D, Oates PJ, Hammes HP, Giardino I \& Brownlee M 2000 Normalizing mitochondrial superoxide production blocks three pathways of hyperglycaemic damage. Nature 404 787-790.

Oberley LW 1988 Free radicals and diabetes. Free Radical Biology and Medicine 5 113-124.

Owens L \& Belcher RV 1965 A colorimetric micro-method for the determination of glutathione. Biochemical Journal 94 75-79.

Perez-Pinzon MA, Xu GP, Born J, Lorenzo J, Busto R, Rosenthal M \& Sick TJ 1999 Cytochrome $C$ is released from mitochondria into the cytosol after cerebral anoxia or ischemia. Journal of Cerebral Blood Flow and Metabolism 19 39-43.

Raha S \& Robinson BH 2000 Mitochondria, oxygen free radical, disease and aging. Trends in Biochemical Science 25 502-508.

Raha S, McEachern GE, Myint AT \& Robinson BH 2000 Superoxide from mitochondrial complex III: the role of manganese superoxide dismutase. Free Radical Biology and Medicine 29 170-180.
Sarkela TM, Berthiaume J, Elfering S, Gybina AA \& Giulivi C 2001 The modulation of oxygen radical production by nitric oxide in mitochondria. Journal of Biological Chemistry 276 6945-6949.

Smith RAJ, Porteous CM, Coulter CV \& Murphy MP 1999 Targeting an antioxidant to mitochondria. European Journal of Biochemistry 263 709-716.

Weigner K \& Jacobson AM 1998 Cognitive impairment in patients with type 1 (insulin-dependent) diabetes mellitus. CNS Drugs 9 233-252.

Yang J, Liu XS, Bhalla K, Kim CN, Ibrado AM, Cai JY, Peng TI, Jones DP \& Wang XD 1997 Prevention of apoptosis by Bcl-2: release of cytochrome $c$ from mitochondria blocked. Science $\mathbf{2 7 5}$ 1129-1132.

Yang SQ, Zhu H, Li Y, Lin HZ, Gabrielson K, Trush MA \& Mae Diehl A 2000 Mitochondrial adaptations to obesity-related oxidant stress. Archives of Biochemistry and Biophysics 378 259-268.

Zoccarato F, Valente M \& Alexandre A 1993 Identification of a $\mathrm{NADH}$ plus iron dependent $\mathrm{Ca}^{2+}$ activated hydrogen peroxide production in synaptosomes. Biochimica et Biophysica Acta 1176 208-214.

Received in final form 19 June 2005

Accepted 1 July 2005 